\title{
TIPO DE ESTACA E CONCENTRAÇÃO DE ÁCIDO INDOLBUTÍRICO NA PROPAGAÇÃO DA LICHIEIRA
}

\author{
Type of cuttings and concentration of indolbutyric acid \\ on the lychee tree propagation
}

\author{
Débora Costa Bastos 1 , Rafael Pio ${ }^{2}$, João Alexio Scarpare Filho ${ }^{3}$, \\ Luis Felipe Paes de Almeida ${ }^{4}$, Fábio Albuquerque Entelmann ${ }^{4}$, \\ André Siqueira Rodrigues Alves ${ }^{4}$
}

\begin{abstract}
RESUMO
Este trabalho foi desenvolvido com o objetivo de estudar o potencial de enraizamento de estacas de lichieira cultivar Bengal, tratadas com diferentes concentrações de ácido indolbutírico. Estacas semilenhosas e lenhosas de lichieira foram coletadas de ramos de plantas matrizes da cultivar Bengal, padronizadas com $12 \mathrm{~cm}$ de comprimento e submetidas à aplicação de quatro concentrações de AIB (0, 2000, 4000 e $\left.6000 \mathrm{mg} \mathrm{L}^{-1}\right)$, em imersão por quinze segundos. Posteriormente, foram colocadas em bandejas de poliestireno, contendo o substrato vermiculita de grânulos médios, sendo transferidas para câmara de nebulização intermitente com umidade e temperatura controladas. O delineamento experimental utilizado foi inteiramente casualizado em arranjo fatorial $2 \times 4$, com 4 repetições e 10 estacas/parcela. Após 130 dias, foram avaliadas as porcentagens de estacas enraizadas, estacas vivas, formação de calos e número de raízes emitidas por estaca. Conclui-se que a o AIB aumenta a porcentagem de estacas enraizadas de lichieira. Estacas semilenhosas apresentam maior potencial de enraizamento em comparação às estacas lenhosas. A utilização da estaquia em lichieira é um método promissor na produção de mudas dessa frutífera.
\end{abstract}

Termos para indexação: Litchi chinensis Soon., estaquia e regulador de crescimento.

\begin{abstract}
This work was carried out with the objective to study rooting potential of lychee cuttings cultivar Bengal treated with different concentrations of indolbutyric acid (IBA). Semi hardwood and hardwood cuttings of lychee tree were collected of branches of stock plants of cultivar Bengal standardized with $12 \mathrm{~cm}$ of length, and submitted to application of four concentrations of IBA $(0$, $2,000,4,000$, and $6,000 \mathrm{mgL}^{-1}$ ) for 15 seconds immersion. Later the cuttings were placed in polyestyrene trays containing vermiculite as substrate and maintained in greenhouse under intermittent mist with moistness and temperature controlled. The experimental design was completely randomized, with the factorial $2 \times 4$, with 4 replicates and 10 cuttings each plot. After 130 days, the rooting percentage, survival percentage, callus formation percentage and medium root number per cuttings were evaluated. It was conclued that the IBA increases the rooting percentage of lychee cuttings. Semi hardwood cuttings showed higher the rooting potential in comparison with the hardwood cuttings. The utilization of lychee cuttings is a method applied in the changes production of this fruitful.
\end{abstract}

Index terms: Litchi chinensis Soon., cuttings and growth regulator.

(Recebido para publicação em 22 de junho de 2005 e aprovado em 18 de outubro de 2005)

\section{INTRODUÇÃO}

A lichieira (Litchi chinensis Soon.) é uma planta da família Sapindaceae, originária do sul da China, adaptada às regiões tropicais e subtropicais. A China é o principal país produtor de lichia, tendo como produção anual cerca de 1.300.000 toneladas (MENZEL, 2002). No Brasil, existe uma carência de informações relativas às estatísticas sobre a produção de lichia, e os dados são escassos ou não estão bem determinados. Dentre as principais áreas cultivadas com lichia, 97\% encontram-se no Estado de São
Paulo (Bastos, Taquaritinga, Limeira e outros) (MARTINS et al., 2001a; YAMANISHI et al., 2001).

A produção comercial de mudas de lichia é realizada pelo método da alporquia, porém, este método apresenta a desvantagem de ser oneroso, exigindo mãode-obra especializada. A produção de mudas também pode ser por meio de sementes, entretanto, pode ocorrer variabilidade genética, além das plantas apresentarem um longo período juvenil, levando cerca de dez a doze anos para entrar em produção (MANICA, 2002; MARTINS et al., 2001a).

\footnotetext{
${ }^{1}$ Engenheira Agrônoma, D.Sc. UFLA - Rua Comendador José Esteves, 136 - Centro - 37200-000 - Lavras,MG - dcbfatinansi@gmail.com

2 Engenheiro Agrônomo, D.Sc., PqC. Centro APTA Frutas, IAC - Jundiaí, SP. rafaelpio@iac.sp.gov.br

${ }^{3}$ Engenheiro Agrônomo, Professor Doutor Associado do Departamento. de Produção Vegetal, ESALQ/USP _Piracicaba-SP.

${ }^{4}$ Engenheiro Agrônomo, mestrando em Fitotecnia, Departamento de Produção Vegetal - ESALQ/USP - Piracicaba, SP.
} 
Dessa forma, a propagação desta espécie por meio de estacas pode ser utilizada, entretanto, são poucos os trabalhos realizados, havendo carência em estudos relacionados a esse método.

A estaquia, em espécies de difícil enraizamento pode ser observada, se forem fornecidas condições (uso de reguladores de crescimento) e fatores ótimos para a formação de raízes nas mesmas (MAYER, 2001; OLIVEIRA, 2000). O equilíbrio entre os diversos hormônios tem forte influência na emissão de raízes em estacas. Uma das formas mais comuns de favorecer o balanço hormonal para o enraizamento é a aplicação exógena de reguladores de crescimento, principalmente as auxinas, tais como o ácido indolbutírico (AIB), que eleva o teor de auxinas no tecido (PASQUAL et al., 2001). O AIB é uma auxina altamente efetiva no estímulo ao enraizamento, o que se deve à sua menor mobilidade, menor fotossensibilidade e maior estabilidade química na planta (HARTMANN et al., 2002). Tratamentos com AIB podem promover o aumento da porcentagem de estacas que formam raízes, aceleração da iniciação radicular, aumento do número e qualidade de raízes produzidas e aumento da uniformidade de enraizamento (FACHINELLO et al., 1995).

O processo de formação de raízes em estacas é influenciado por um grande número de fatores que podem atuar isoladamente ou em conjunto. Dentre esses, destacam-se as condições fisiológicas da planta matriz (presença de carboidratos, substâncias nitrogenadas, aminoácidos, auxinas, compostos fenólicos e outras substâncias não identificadas), o período e posição de coleta das estacas, juvenilidade, estiolamento, presença de folhas e gemas, idade da planta matriz e fatores do ambiente como disponibilidade de água, luminosidade e substrato (HARTMANN et al., 2002). O percentual de enraizamento também pode variar com o tipo de estaca utilizada, visto que esse potencial varia entre as diferentes porções de um mesmo ramo. Ramos lenhosos, coletados no inverno, em geral, apresentam maior enraizamento na porção basal, enquanto que ramos coletados em outras épocas, portanto, semilenhosos e herbáceos possuem maior potencial de enraizamento em sua porção apical (FACHINELLO et al., 1995; HARTMANN et al., 2002). Carvalho et al. (2005) observaram maiores taxas de enraizamento $(68,75 \%)$ em estacas semilenhosas de lichieira cultivar Bengal sem o tratamento com AIB. Por outro lado, Martins (1998) verificou maior potencial de enraizamento $(71,11 \%)$ em estacas herbáceas, sem a utilização de AIB. Entretanto, em estacas da mesma espécie, a concentração de $3000 \mathrm{mg} \mathrm{L}^{-1}$ de AIB e o anelamento dos ramos por uma semana antes da coleta das estacas, proporcionaram $69 \%$ de enraizamento (MARTINS et al., 2001b).

Objetivou-se com este trabalho verificar o potencial de enraizamento de estacas semilenhosas e lenhosas de lichieira cultivar Bengal, tratadas com diferentes concentrações de ácido indolbutírico.

\section{MATERIAL E MÉTODOS}

O experimento foi conduzido em março de 2004, na área de produção de mudas do Departamento de Produção Vegetal da Universidade de São Paulo, Escola Superior de Agricultura "Luiz de Queiroz" - USP/ESALQ, Piracicaba-SP.

As estacas semilenhosas foram retiradas da porção apical de ramos jovens e as estacas lenhosas retiradas da porção basal de ramos lignificados (do ano anterior), ambas de plantas matrizes de lichieiras cultivar Bengal, com 15 anos de idade, pertencentes ao Núcleo de Produção de Mudas da CATI (Coordenadoria de Assistência Técnica Integral) de Tietê-SP. Estas foram preparadas com $12 \mathrm{~cm}$ de comprimento, sendo efetuado um corte horizontal no ápice e em bisel na extremidade basal, conservando-se um par de folhas na porção apical da estaca. Posteriormente, as estacas foram tratadas com ácido indolbutírico diluído

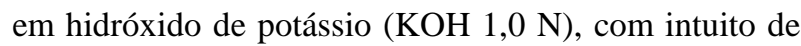
facilitar a posterior diluição e homogeneização em água destilada, nas concentrações de 0, 2000, 4000 e 6000 mg L${ }^{1}$, imergindo $2 \mathrm{~cm}$ da sua base durante 15 segundos. Em seguida foram colocadas em bandejas de poliestireno contendo como substrato vermiculita de grânulos médios, em casa-de- vegetação sob nebulização intermitente (temperatura de $25 \pm 5^{\circ} \mathrm{C}$, UR média de $72 \%$, tempo de aspersão de 20 segundos em intervalos de 10 minutos).

Após 130 dias, foram avaliadas as porcentagens de estacas enraizadas e vivas, formação de calos e o número de raízes por estaca. $O$ delineamento experimental utilizado foi inteiramente casualizado, em arranjo fatorial $2 \times 4$, sendo o fator tipo de estaca representado por dois níveis (estacas semilenhosas e estacas lenhosas) e o fator AIB por quatro níveis $\left(0,2000,4000\right.$ e $\left.6000 \mathrm{mg} . \mathrm{L}^{-1}\right)$, com quatro repetições e unidade experimental composta por 10 estacas. Os dados experimentais foram submetidos à análise de variância, as médias, ao teste Tukey a 5\% de probabilidade (GOMES, 2000). Os dados de porcentagem foram transformados em $\operatorname{arcsen} \sqrt{x+0,5}$.

\section{RESULTADOS E DISCUSSÃO}

Pode-se observar pela análise de variância, o efeito significativo do tipo de estaca e da utilização de AIB na formação de raízes nas estacas, porém, a interação entre

Ciênc. agrotec., Lavras, v. 30, n. 1, p. 97-102, jan./fev., 2006 
esses dois fatores não foi significativa. Verifica-se ainda que não houve efeito significativo da utilização de AIB e dos tipos de estacas para as porcentagens de sobrevivência e formação de calos nas estacas testadas. Para o número de raízes emitidas por estaca, observa-se apenas o efeito significativo do tipo de estaca utilizado (Quadro 1).

Para a porcentagem de estacas enraizadas (Tabela 1), pode-se observar o incremento desta variável com a utilização de AIB (Figura 1). Houve aumento linear da porcentagem de estacas enraizadas com a submissão das crescentes concentrações de AIB, obtendo-se sem a utilização dessa auxina apenas $13,57 \%$ de enraizamento, porém com $6000 \mathrm{mg} . \mathrm{L}-$ ${ }^{1}$ foi possível obter-se $50,17 \%$ de enraizamento, incremento de $36,6 \%$ de estacas enraizadas (Figura 1).

Tal fato provavelmente ocorreu, devido a aplicação de concentrações mais altas de auxinas nas estacas.
Teoricamente, as auxinas desempenham um papel de indução de enraizamento, e quando aplicadas em concentrações mais elevadas, podem favorecer a formação de raízes, como o observado nesse caso, quando se utilizou $6000 \mathrm{mg} \mathrm{L}^{-1}$ de AIB (Figura 2). Entretanto, isso se aplica em determinadas espécies, como observado em estacas de pessegueiro (DUTRA el al., 1998) e de ameixeira (DUTRA et al., 2002).

Por outro lado, elevadas concentrações de AIB quando aplicadas em estacas de determinadas espécies, como em estacas de caramboleira (BASTOS et al., 2004), podem causar fitotoxicidade e inibir a formação de raízes e o enraizamento. Carvalho et al. (2005) concluíram que não há necessidade da aplicação de AIB para o enraizamento de estacas semilenhosas de lichieira cultivar Bengal, sendo os melhores resultados observados quando não se utilizou regulador de crescimento $(68,75 \%)$.

QUADRO 1 - Análise de variância das porcentagens de estacas enraizadas (PEE), estacas vivas (PEV), formação de calos (PFC) e número de raízes por estaca (NRE) de estacas de lichieira cultivar Bengal, em função de diferentes tipos de estacas e das concentrações de AIB. ESALQ/USP, Piracicaba - SP, 2004.

\begin{tabular}{|l|c|c|c|c|c|}
\hline \multicolumn{1}{|c|}{ Causas da variação } & GL & PEE & PEV & PFC & NRE \\
\hline Tipo de estaca (A) & 1 & $5,05^{*}$ & $1,41^{\text {ns }}$ & $0,75^{\text {ns }}$ & $4,17^{*}$ \\
\hline AIB (B) & 3 & $4,62^{*}$ & $2,77^{\text {ns }}$ & $1,80^{\text {ns }}$ & $0,29^{\text {ns }}$ \\
\hline A x B & 3 & $0,24^{\text {ns }}$ & $0,66^{\text {ns }}$ & $0,35^{\text {ns }}$ & $0,53^{\text {ns }}$ \\
\hline Resíduo & 24 & - & - & - & - \\
\hline cv (\%) & - & 37,17 & 7,89 & 11,09 & 48,15 \\
\hline DMS & - & 14,35 & 5,42 & 7,41 & 2,05 \\
\hline
\end{tabular}

ns: não-significativo.

*: significativo $(P<0,05)$

TABELA 1 - Porcentagens de estacas enraizadas (PEE), estacas vivas (PEV), formação de calos (PFC) e número de raízes por estaca (NRE) de lichieira cultivar Bengal, em função dos tipos de estacas. ESALQ/USP, Piracicaba-SP, 2004.

\begin{tabular}{ccccc}
\hline \multirow{2}{*}{ Tipos de estacas } & \multicolumn{4}{c}{ Variáveis Analisadas } \\
\cline { 2 - 5 } & PEE (\%) & PEV (\%) & PFC (\%) & NRE \\
\hline Semilenhosa & $38,75 \mathrm{a}$ & $95,62 \mathrm{a}$ & $93,12 \mathrm{a}$ & $5,21 \mathrm{a}$ \\
Lenhosa & $23,12 \mathrm{~b}$ & $92,50 \mathrm{a}$ & $90,00 \mathrm{a}$ & $2,97 \mathrm{~b}$ \\
\hline CV $(\%)$ & 33,54 & 7,89 & 11,09 & 35,52 \\
\hline
\end{tabular}

Médias seguidas de letras distintas, na coluna, diferem estatisticamente entre si ao nível de 5\% de probabilidade, pelo teste Tukey. 


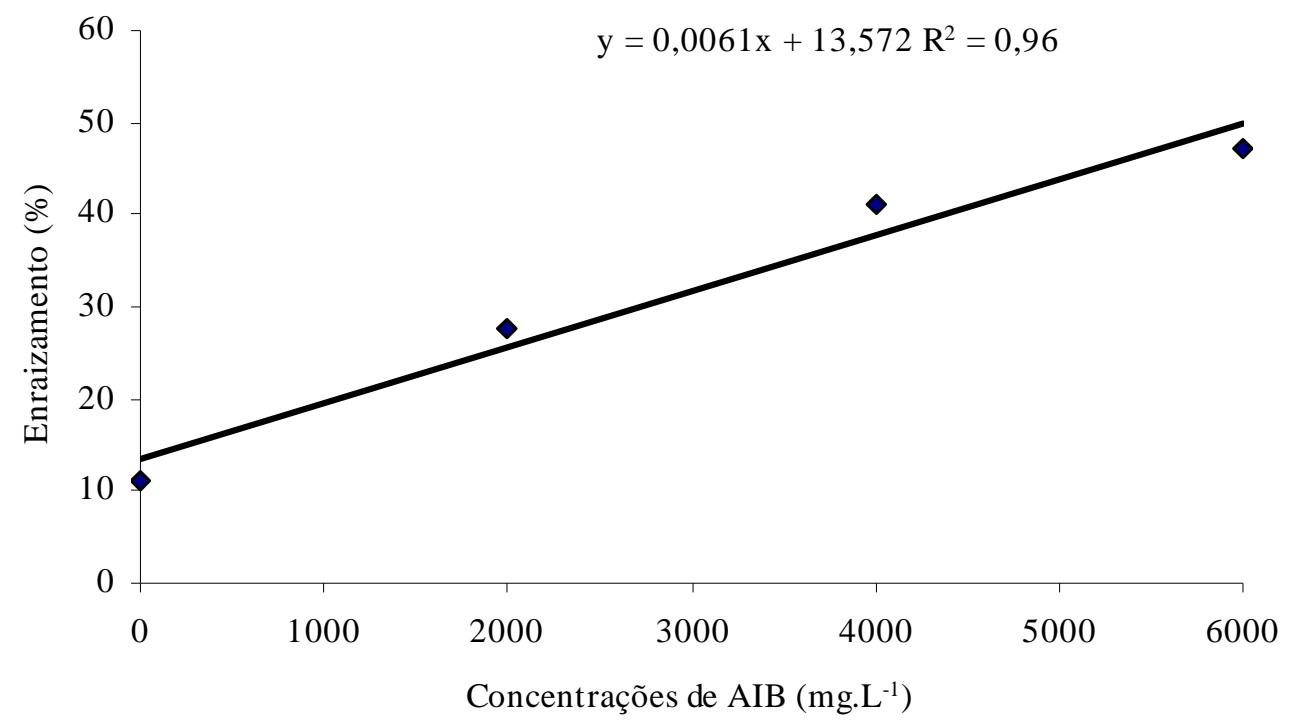

FIGURA 1 - Porcentagem de enraizamento de estacas de lichieira em função das concentrações de AIB testadas. ESALQ/USP, Piracicaba, SP, 2004.
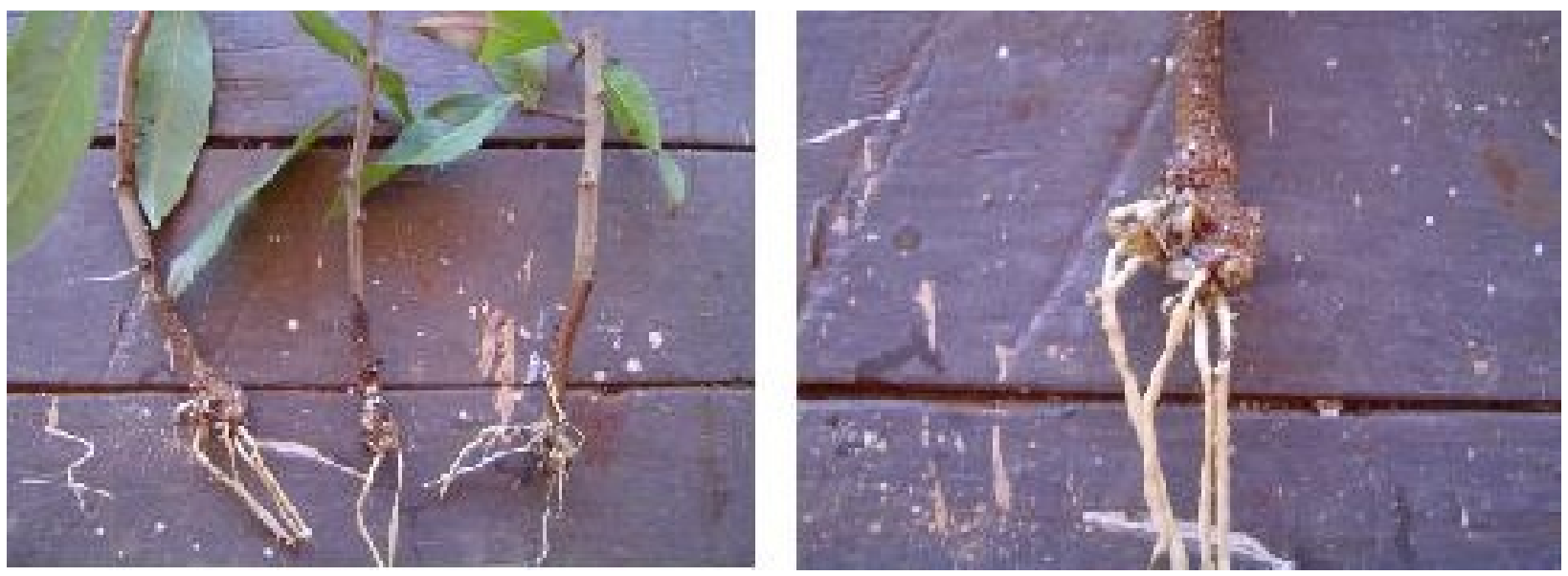

FIGURA 2 - Aspecto da formação de raízes em estacas semilenhosas de lichieira cultivar Bengal submetidas a $6000 \mathrm{mg} \mathrm{L}^{-1}$ de AIB.

Para o número de raízes emitidas por estacas, verifica-se o efeito significativo do tipo de estaca utilizado, sendo as estacas semilenhosas as que apresentaram maior número de raízes por estaca $(5,21)$ em relação às estacas lenhosas $(2,97)$, semelhantes às respostas observadas para porcentagem de enraizamento (Tabela 1).

Embora não tenha ocorrido diferença significativa para as porcentagens de estacas vivas e formação de calos, verifica-se pela Tabela 1 , que a taxa média de estacas vivas e formação de calos apresentada pelas estacas semilenhosas e lenhosas foi de $95,62 \%$ e $92,5 \%$ e $93,12 \%$ e $90 \%$, respectivamente. Tal fato pode ser explicado pelo alto teor de lignina contido nos tecidos das estacas. Geralmente, estacas semilenhosas e lenhosas apresentam maior capacidade de sobrevivência, pois são menos sensíveis à desidratação e à morte (HARTMANN et al., 2002).

Com relação à aplicação de AIB, não houve diferença significativa no número de raízes entre as concentrações testadas (Tabela 2). 
TABELA 2 - Porcentagens de estacas enraizadas (PEE), vivas (PEV), formação de calos (PFC) e número de raízes por estaca (NRE) de estacas de lichieira cultivar Bengal, em função das concentrações de AIB. ESALQ/USP, Piracicaba-SP, 2004.

\begin{tabular}{ccccc}
\hline \multirow{2}{*}{ AIB $\left(\mathbf{m g ~ L}^{-\mathbf{1}}\right)$} & \multicolumn{4}{c}{ Variáveis Analisadas } \\
\cline { 2 - 5 } & PEE $(\boldsymbol{\%})$ & PEV $(\boldsymbol{\%})^{*}$ & PFC $(\boldsymbol{\%})^{*}$ & NRE* $^{*}$ \\
\hline 0 & $11,25 \mathrm{~b}$ & $96,25 \mathrm{a}$ & $88,75 \mathrm{a}$ & $4,66 \mathrm{a}$ \\
2000 & $27,50 \mathrm{ab}$ & $96,25 \mathrm{a}$ & $95,00 \mathrm{a}$ & $4,00 \mathrm{a}$ \\
4000 & $41,25 \mathrm{a}$ & $96,25 \mathrm{a}$ & $96,25 \mathrm{a}$ & $4,40 \mathrm{a}$ \\
6000 & $43,75 \mathrm{a}$ & $87,50 \mathrm{a}$ & $86,25 \mathrm{a}$ & $3,31 \mathrm{a}$ \\
\hline CV $(\%)$ & 33,54 & 7,89 & 11,09 & 35,52 \\
\hline
\end{tabular}

* Médias seguidas de mesma letra na coluna, não diferem pelo teste $\mathrm{F}$ da análise de variância.

Resultados semelhantes foram observados por Bastos (2002) em estacas de caramboleira. Martins (1998) não observou efeito significativo da aplicação de AIB em estacas de lichieira, sendo as estacas sem tratamento com o regulador as que apresentaram melhores potenciais de enraizamento (71,11\%). Entretanto, Oliveira (2000), em estacas de maracujazeiro, obteve incrementos crescentes para o número de raízes por estacas com concentrações crescentes de AIB. Mayer (2001) obteve bons resultados de enraizamento e número de raízes utilizando $2000 \mathrm{mg} \mathrm{L}^{-1}$ de AIB em estacas de umezeiro.

Não houve diferença significativa entre as concentrações aplicadas, na porcentagem de estacas vivas e na formação de calos dos dois tipos de estacas estudados (Tabela 2). Entretanto, pode-se ressaltar que tanto para a sobrevivência como para a formação de calos, as estacas apresentaram porcentagens elevadas $(96,25 \%$ de sobrevivência e $96,25 \%$ de formação de calos), semelhante ao observado para os tipos de estacas.

\section{CONCLUSÕES}

a) O AIB aumentou a porcentagem de estacas enraizadas de lichieira;

b) Estacas semilenhosas apresentam maior potencial de enraizamento em comparação às estacas lenhosas na época estudada;

c) A utilização da estaquia em lichieira é um método que necessita de maiores estudos, podendo ser promissor na produção de mudas dessa frutífera.

\section{REFERÊNCIAS BIBLIOGRÁFICAS}

BASTOS, D. C. Efeito da época de coleta, estádio do ramo e do tratamento com IBA no enraizamento de estacas de caramboleira (Averrhoa carambola L.). 2002. 75 f.
Dissertação (Mestrado em Agronomia) - Faculdade de Ciências Agrárias e Veterinárias, Universidade Estadual Paulista, Jaboticabal, 2002.

BASTOS, D. C.; MARTINS, A. B. G.; SCALOPPI JUNIOR, E. J.; SARZI, I.; FATINANSI, J. C. Influência do ácido indolbutírico no enraizamento de estacas apicais e basais de caramboleira (Averrhoa carambola L.) sob condições de nebulização intermitente. Revista Brasileira de Fruticultura, Jaboticabal, v. 26, n. 2, p. 284-286, 2004.

CARVALHO, C. M.; CUNHA, R. J. P.; RODRIGUES, J. D. Enraizamento de estacas semilenhosas de lichieira utilizando ácido indolbutírico. Revista Brasileira de Fruticultura, Jaboticabal, v. 27, n. 1, p. 95-97, 2005.

DUTRA, L. F.; KERSTEN, E.; FACHINELLO, J. C. Época de coleta, ácido indolbutírico e triptofano no enraizamento de estacas de pessegueiro. Scientia Agricola, Piracicaba, v. 59, n. 2, p. 327-333, 2002.

DUTRA, L. F.; TONIETTO, A.; KERSTEN, E. Efeito da aplicação prévia de ethephon em ameixeira (Prunus salicina Lindl) e do IBA no enraizamento de suas estacas. Scientia Agricola, Piracicaba, v. 55, n. 2, p. 296304, 1998.

FACHINELLO, J. C.; HOFFMANN, A.; NACHTIGAL, J. C.; KERSTEN, E.; FORTES, G. R. de L. Propagação de plantas frutíferas de clima temperado. 2. ed. Pelotas: UFPel, 1995. $179 \mathrm{p}$.

GOMES, F. P. Curso de estatística experimental. 14. ed. Piracicaba: USP/ESALQ, 2000. 477 p. 
HARTMANN, H. T.; KESTER, D. E.; DAVIES JUNIOR, F. T.; GENEVE, R. L. Plant propagation: principles and practices. 7. ed. New Jersey: Prentice Hall, 2002. 880 p.

MANICA, I. Frutas nativas, silvestres e exóticas 2: técnicas de produção e mercado: feijoa, figo da índia, fruta pão, jaca, lichia, mangaba. Porto Alegre: Ed. Cinco Continentes, 2002. $541 \mathrm{p}$.

MARTINS, A. B. G. Enraizamento de estacas enfolhadas de três variedades de lichia (Litchi chinensis Sonn.). 1998. 100 f. Tese (Doutorado em Agronomia) - Faculdade de Ciências Agrárias e Veterinárias, Universidade Estadual Paulista, Jaboticabal, 1998.

MARTINS, A. B. G.; BASTOS, D. C.; SCALOPPI JUNIOR, E. J. Lichieira (Litchi chinensis Soon.). Jaboticabal: Sociedade Brasileira de Fruticultura, 2001a. 48 p. (Série Frutas Potenciais).

MARTINS, A. B. G.; SCALOPPI JUNIOR, E. J.; BASTOS, D. C. Estaquia herbácea com anelamento prévio dos ramos de lichia (Litchi chinensis Soon.) cvs. Brewster e Sweet Cliff. In: CONGRESSO BRASILEIRO DE FISIOLOGIA VEGETAL, 8., 2001, Ilhéus. Anais... Ilhéus: SBF, 2001b. CD-ROM.
MAYER, N. A. Propagação assexuada do porta-enxerto umezeiro (Prunus mume Sieb \& Zucc.) por estacas herbáceas. 2001. 109 f. Dissertação (Mestrado em Produção Vegetal) - Faculdade de Ciências Agrárias e Veterinárias, Universidade Estadual Paulista, Jaboticabal, 2001 .

MENZEL, C. M. The lychee crop in Ásia and the pacific. Bangkpk: FAO, 2002. 108 p.

OLIVEIRA, J. A. Efeito dos substratos artificiais no enraizamento e no desenvolvimento de maracujazeiroazedo e doce por estaquia. 2000. 71 f. Dissertação (Mestrado em Agronomia) - Universidade de Brasília, Brasília, DF, 2000.

PASQUAL, M.; CHALFUN, N. N. J.; RAMOS, J. D.; VALE, M. R. do; SILVA, C. R. de R. e. Fruticultura comercial: propagação de plantas frutíferas. Lavras: UFLA/FAEPE, 2001. 137 p.

AMASHINI, O. K.; MACHADO FILHO, J. A.; KAVATI, R. Overview of litchi production in São Paulo State, Brazil. Acta Horticulturae, Wageningen, n. 558, p. 5962, 2001. 